\title{
System Behaviour Charts Inform an Understanding of Biodiversity Recovery
}

\author{
Simon A. Black ${ }^{1,2}$ \\ ${ }^{1}$ Durrell Institute for Conservation and Ecology, University of Kent, Canterbury CT2 7NZ, UK \\ ${ }^{2}$ Durrell Conservation Academy, Durrell Wildlife Conservation Trust, Trinity, Jersey, Channel Islands, UK
}

Correspondence should be addressed to Simon A. Black; s.black@kent.ac.uk

Received 14 July 2015; Accepted 8 October 2015

Academic Editor: Béla Tóthmérész

Copyright (C) 2015 Simon A. Black. This is an open access article distributed under the Creative Commons Attribution License, which permits unrestricted use, distribution, and reproduction in any medium, provided the original work is properly cited.

\begin{abstract}
Practitioners working with species and ecosystem recovery typically deal with the complexity of, on one hand, lack of data or data uncertainties and, on the other hand, demand for critical decision-making and intervention. The control chart methods of commercial and industrial and environmental monitoring can complement an ecological understanding of wildlife systems including those situations which incorporate human activities and land use. Systems Behaviour Charts are based upon wellestablished control chart methods to provide conservation managers with an approach to using existing data and enable insight to aid timely planning of conservation interventions and also complement and stimulate research into wider scientific and ecological questions. When the approach is applied to existing data sets in well-known wildlife conservation cases, the subsequent Systems Behaviour Charts and associated analytical criteria demonstrate insights which would be helpful in averting problems associated with each case example.
\end{abstract}

\section{Introduction}

Conservation biology operates across the boundary between science and practice [1]. Practitioners working in the field need to make decisions and interventions concerning landscape management, release or translocation of animal populations, animal health, captive breeding, planting of habitats, removal of invasive species (e.g., cats, rats, monkeys, and insects), and education of local people or negotiating with local or international communities on aspects such as livestock management, agriculture, hunting, or commercial enterprise. Conservation typically encounters uncertainty [2] and often a need to take quick action, but with little data. For example, critically endangered species may survive in tiny numbers, such as the Mauritius kestrel which persisted at its lowest ebb with just a single breeding pair $[1,3]$, or a species may face a rapidly developing threat, such as the recent disease outbreak in Saiga antelope [4]. One difficulty is achieving controlled experiments and hypothesis testing in a way that is relevant to the needs of practical conservation. Relevant improvements (such as recovering a population of a threatened species) arise from understanding the behaviour of the ecosystem of concern, usually over periods of change. As such, a temporal understanding of data is helpful.

Deming describes this particular competency as understanding the theory of variation $[5,6]$. Well-established methods of analysis have arisen from Shewhart's [7] work on variation using visual charts, analysis, and decision-making; the "Method of Continual Improvement" [8], which is known in industrial applications as Statistical Process Control; or "Systems Thinking" [9]. Use of control charts has previously been recommended for natural resource monitoring [10], whilst the "Systems Thinking" approach has been suggested for improving conservation effectiveness [11]. Shewhart's [7] work in the 1920s and 1930s was based upon the realisation that data contains both "signal" and "noise" and that there are two kinds of variability in outputs: controlled variability (common cause) due to the system itself (e.g., its components, communities, and resources) and uncontrolled variability (special cause) from sources essentially outside the system.

"Common cause" variation is the net result of multiple influences "built in" to the system [6] and cannot 
be attributable to a person or particular intervention (in ecosystems this relates to aspects such as species, landscape, and climate). Any attempt to make an attribution and attempt to fix or amplify the outcome will only complicate the situation and will worsen the outcome [12]. Instead, effort should go into changing the system itself (methods, processes, measures, and rewards).

"Special cause" variation is a unique event that is attributable to some knowable influence [13], being an exceptional occurrence (e.g., "outliers," one-offs, or unusual patterns). An accidental oil spillage on a coastal ecosystem could be one example (although if such occurrences were regularly encountered, such as in heavily polluted or unregulated shipping highways, it would be a common cause). Exceptional causes differ in that their solution lies in correctly identifying that attributable problem outside the system and either eliminating it at its origin (if it causes a decline in the ecosystem) or identifying whether insights into future permanent improvement can be gained.

\section{Methods for Understanding Variation: "Systems Behaviour Charts"}

Systems Behaviour Charts, based upon the control charts concept [7], offer a method to use existing data in answering practical conservation questions. The term "System Behaviour Charts" is derived from Wheeler's [8] industrial "process behaviour charts" since wildlife ecosystems arise from the interactions of multiple processes (sometimes both natural and man-made). The purpose of the chart is to monitor and differentiate stable, predictable ups and downs in the data (due to common causes) from exceptional variation: to prompt reaction to apparent changes only if they are detected to be, in some sense, statistically significant $[8,10]$. Systems monitoring, using data in this manner, resembles continuous statistical hypothesis testing [13]. The charts allow observation of the predictability (or capability) of a system $[7,9]$ and typically involve longitudinal plots of data over time compared with plots of mean and measures of spread across the data (e.g., plots at mean \pm 3 standard deviations). This collection of data is termed a sequential sample [14] and the ordering as a time-series is critical. Drawing on previous definitions the logic follows that $[7,8]$

a system will be said to be predictable when, through the use of past data we can describe, at least within limits, how the process will behave in the future.

Conservation processes can be identified on charts as predictable or unpredictable from data arising from those systems over time. Data points can be plotted and observed in relation to natural limits, limits for averages (means), and limits for ranges derived from empirical data. Systems Thinking focuses on the improvement of conservation work to meet the needs of species and ecosystems [15].

2.1. Understanding Predictability. A system is defined as predictable (stable), where almost all outcome data fit within upper and lower natural limits [8]. The limits are defined for practical purposes as an upper natural limit of mean +3 standard deviations and a lower natural limit of mean -3 standard deviations derived from the data observed. The outcomes of a stable system may or may not be unacceptable, but predictability allows consideration of potential improvements. Essentially, the system can do no better than the performance levels expressed by the mean and natural limits in the data [8]. The only way to change the outcomes is to change the system. Improvement of a predictable system involves working on the system, not responding to isolated ups and downs in the data.

2.2. Understanding Unpredictability or Unstable Systems. A system which is unpredictable includes both routine variation and exceptional variation. Assignable causes (those which cause exceptional changes in the data) will dominate the common causes (routine variation). Any attempt to seek a special explanation for those unacceptable outcomes would be a waste of time [8]. As Wheeler [8] points out, "the best you can say is that tomorrow is another day." For these processes predicting next week's or next month's outcomes, even within limits, is impossible. In unpredictable processes, any signal in the data will be evidence of an assignable cause. However a change to accommodate an assignable (i.e., exceptional or special) cause will be worth investigating. When assignable causes are eliminated (if possible) the stability of the process should be improved until it becomes predictable, with data points returning to within natural limits. Assignable causes provide the practitioner with learning opportunities and insights into potential improvements. However a change to accommodate an exceptional cause will do nothing to change the underlying system.

2.3. Detection of Helpful Signals Encountered in Data. Patterns of data plotted on a Systems Behaviour Chart indicate whether there is a presence or influence of a special cause of variation, and whether anything out-of-the-ordinary has occurred [25]. If an exception is indicated this should initiate a search for the cause. Some exceptional variation will be a one-off which could be ignored (i.e., unlikely to happen again); another case will be a one-off which could be helpful to understand (to inform systems improvement); another may indicate that a new factor has come into play and the system has fundamentally changed. All of these things are important to know and understand. Shewhart [26] did not consider statistical control as either estimation nor an approach for testing a hypothesis. Instead, Shewhart considered the approach as a rule of behavior which aims to offset two specific sources of mistake: either (i) looking for special causes too often (or overadjusting) or (ii) not looking for special (i.e., exceptional) causes often enough.

Empirical studies since the 1920s have identified several rules which can be applied to data sets of 20 or more data points. The rules for understanding Systems Behaviour Charts should become established mental tools for perceiving changes in systems behaviour and identifying signals when 
(1) any data point lies outside the natural limits of the process (e.g., mean $\pm 3 \mathrm{SD}$ );

(2) any two consecutive data points lie outside $\pm 2 \mathrm{SD}$;

(3) three or four consecutive points are closer to limits than to the central line [8];

(4) a sequence of seven, eight, or more data points is above the mean or below the mean $[8,25]$;

(5) there is a run of seven decreasing data points or seven increasing data points [25];

(6) cycles above and below the mean suggest that more than one process exists [25];

(7) broadly repeating patterns in data indicate subsets of data to investigate [25];

(8) a natural limit defined from the data sits outside the acceptable range (e.g., for an endangered population of birds, a lower natural limit for the number of breeding pairs sits below the extinction level of zero). Such data indicates a need to fundamentally change the system to ensure that new outcomes feature regularly and predictably only within an acceptable range (i.e., potential extinction of the species should not be tolerated, so in this example the lower natural limit for breeding pairs of birds must be greater than zero) and effort should aim to attain that situation.

In the conservation setting, small data sets might account for all known data, for example, annual census data for an endangered species. The eight criteria for identifying signals provide new insight within economically and rationally prudent limits. Below, the Systems Behaviour Chart method identifies new insights from the data arising from several well-known wildlife conservation cases.

\section{Identifying Changes in Systems: Observations and Insights}

Plots of twenty or more data points may identify different patterns in the data over time [25] signalling the need for a reanalysis of each segment of the "run" of data. If the capability of the system at each segment of the run is different, this should prompt investigation. The following examples from a variety of natural wildlife systems demonstrate the usefulness of this type of analysis.

\subsection{Detecting Important Changes in the System: The Florida} Manatee. The Florida manatee (Trichechus manatus latirostris) is an aquatic sirenian inhabiting the coastal waters and estuaries of Florida, where one of the important threats is fatal collision with boats. When 20 points of data on manatee collision deaths (from 1974 to 1993) are plotted (Figure 1) there appears to be an upward "trend," but when checked against Shewhart chart rules (seven above the mean) three different stable systems appear: the first from 1978, the second from 1984, and a third from 1998. The system has restabilised after 1998, albeit with a high level of manatee collision deaths. The first increase in deaths stabilises from 1978 when

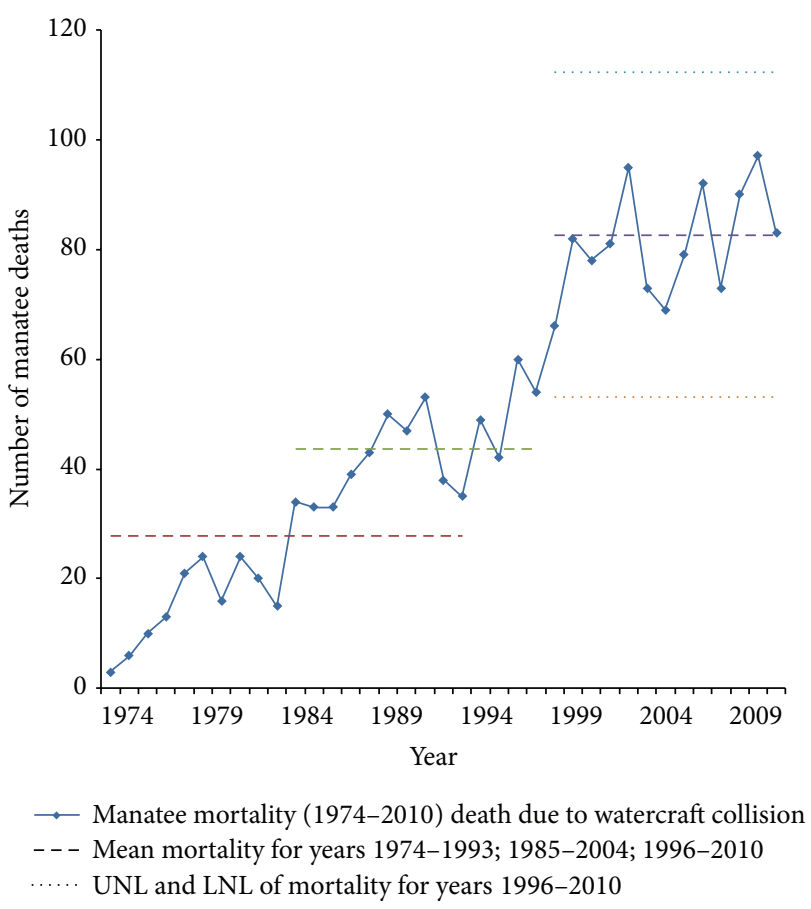

FIGURE 1: Deaths of Florida manatees due to watercraft collisions, showing changes in mean mortality (data from [16-18]).

the Florida Manatee Sanctuary Act enabled authorities to regulate boat speeds. The second occurs when county-level slow speed buffer zones were adopted in Florida. The current system, following a sharp increase in mortality, stabilises with a high level of deaths. The number of registered boats accelerated from 1984 to 1990 and again from 1994 to 1999 [17] which appears to explain the "jumps" in the data. Conservation effort should focus on factors which influenced each change in the system and whether those or other factors could help, hinder, or secure future manatee survival. For each system, all data sit within natural limits, so aside from the steps between each system, "ups" and "downs" in the data are random noise.

3.2. Identifying Signals of Stability or Change in the System. The Puerto Rican amazon parrot (Amazona ventralis vittata) declined significantly during the 1950 s and 1960s. A temporal plot of population census data (regardless of spread between dates) reveals a pattern (Figure 2). Four observable systems occur: the initial decline from 1954, the apparently stable, but cycling system from 1966 to 1982 (note: the repeating increase and decline patterns from 1970 to 1972, 1973 to 1974, and 1975 to 1976 are an amplification of frequent monitoring in those years but does not affect the observed stability of the system, albeit at dangerously low population levels), third, an improved, but less predictable system from 1983 to 2006, and finally a potentially improving fourth system apparent from 2007. The number of data points within these systems is small ( 10 data points), but inferences can still be made by using the principles for analysing System Behaviour Charts. Hurricanes have proven to have particular impact 


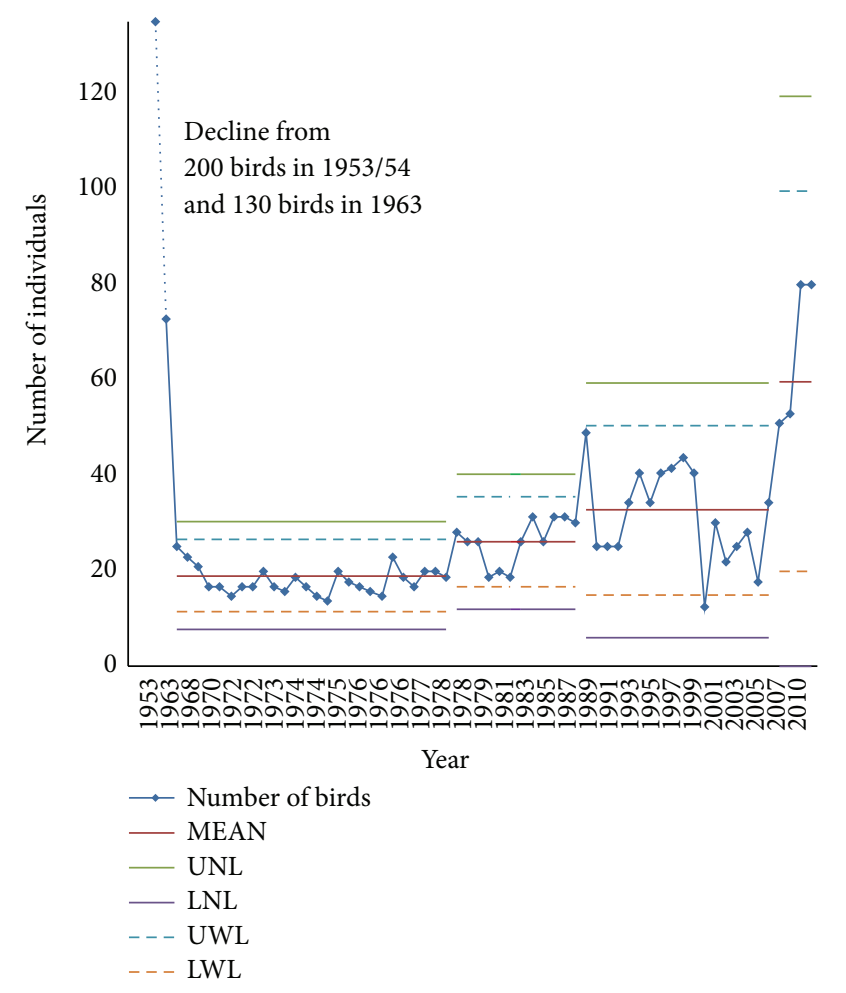

FIgURE 2: Population counts of wild Puerto Rican parrots showing natural limits and warning limits (data from [19-21]).

on parrot survival. Hurricane Hugo impacted Puerto Rico in 1989, hence the drop. Hurricane Georges impacted in September 1998 causing major losses in parrots, identified in the 1999/2000 population data. The Systems Behaviour Chart allows a separation of these external events (and therefore how to mitigate their effects) from an understanding of the general improvement in the parrot population (which can be managed more systemically). Whilst in 2006 a positive "jump" is apparent in the data, conservation must show precaution since the upper and (not shown) lower natural limits' system suggests wide fluctuations including possibility of low-end extinction level populations $(\mathrm{LNL}=$ zero).

\subsection{Earlier Detection of a Dangerous Decline: The Idaho} Ground Squirrel. The Idaho Ground Squirrel (Spermophilus brunneus brunneus) appears in a restricted location in the Midwest of the USA and is a species with limited population data. Even without plotting natural limits, the number of mature females at Squirrel Valley (indicated by open circle data points plotted in Figure 3) indicates that the population is in exceptional decline and the system is "out of control." This might seem obvious when observing the full trend through to 1999; however by the end of the 1990s the situation had already declined past possible recovery (by 2000 the local population was extinct); earlier detection would have prevented this outcome. Whilst the overall downward progression in the total population data is only clear by 1999 (seven below the mean), the "number of females" indicates a critical decline by 1996 when 20 females of breeding age

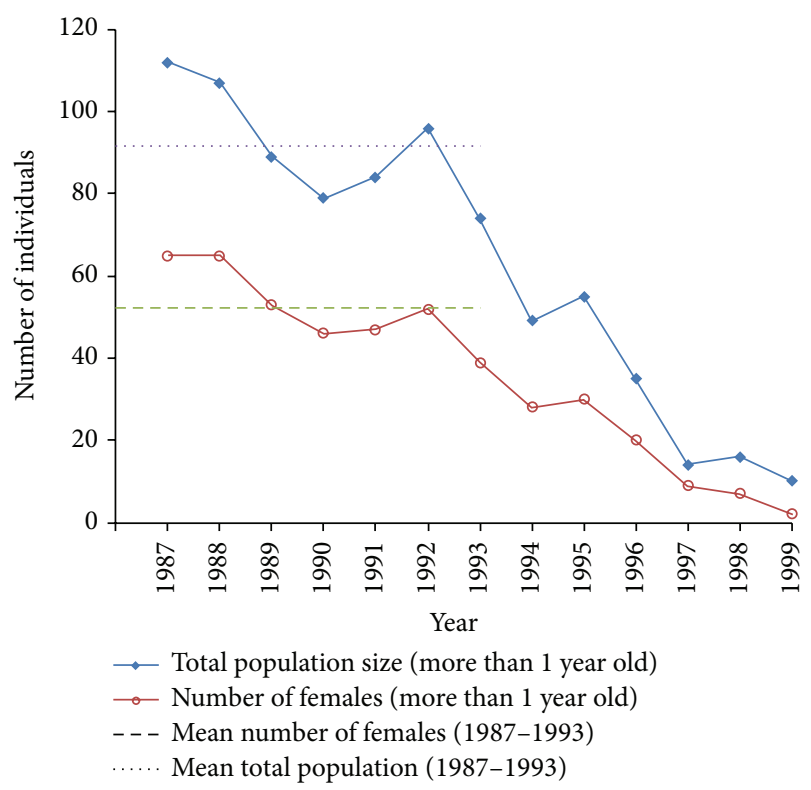

FIGURE 3: Northern Idaho Ground Squirrel population at Squirrel Valley, Idaho (data from [22]).

still remained present. In this instance there is no need for a full set of 20 data points to observe this trend. The Systems Behaviour Chart indicates systemic decline in the female population by 1996. If it had been known at the time, the insight would have provided three years "head start" on conservation effort (with 20 females) as opposed to the discovery of the final extinction of the population in 1999. Had practitioners known this earlier and intervened, straightforward landscape management would most likely have aided population recovery.

3.4. Detecting Vulnerability in a Rare, Cryptic Species: The Poouli in Hawaii. The Poouli (Melamprosops phaeosoma) is a rarely observed endemic Hawaiian Forest bird only discovered in 1973. Although the Hawaiian Forest Bird Survey (1980) estimated the population at $140 \pm 280$ (95\% CI) individuals, very few individuals have ever been sighted in any one year. Observations between 1981 and 1987 showed a year-on-year decline in sightings (Figure 4). Observations were not achieved every year, so the data set is incomplete, a practical reality of working with a cryptic species in difficult terrain with limited resources. An attempt to describe the decline even between the 1981 high of 15 individuals through to 6 individuals in 1995 is somewhat speculative. However, calculation of natural limits (Mean $\pm 3 \mathrm{SD}$ ) for either the tiny data set from 1974 up to 1988 , or more cautiously up to 1996 , or even, more prudently, for the whole data set up to 2003, presents a startling fact. The lower natural limit is negative (LNL $=-6$ individuals, $-6.4,-5.6$, and -5.8 for each sample set). Although strictly speaking the data measures the predictability of observing birds in a given year, had this insight been available in 1988, this would have indicated that the population was at a critical stage. The Poouli population at this point in time was just as likely to go extinct in the next 


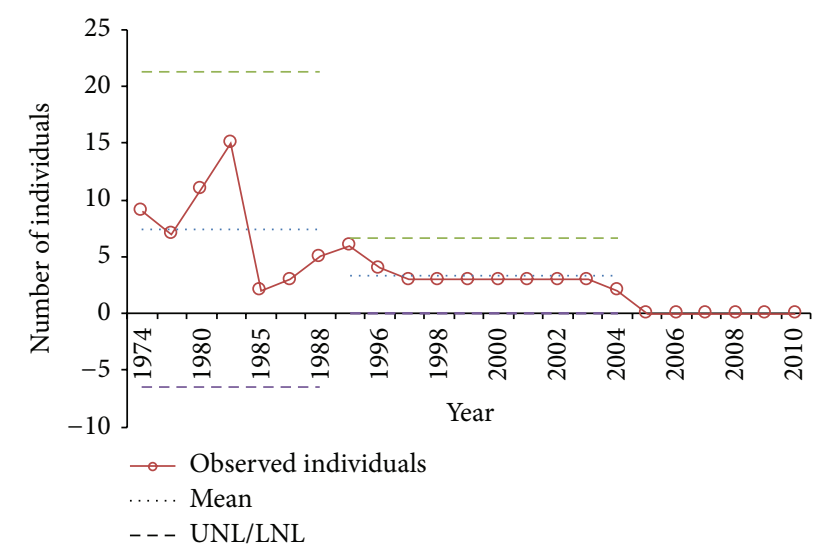

Figure 4: Observation data for the Poouli (Melamprosops phaeosoma) on Maui, Hawaii (data from [11, 23]). Mean and natural limits are calculated for 1974-1988 (left) and 1988-2004 (centre).

year as it was to grow, unless something was changed. The bird was not "naturally rare" (as was debated at the time); a naturally rare bird would have natural limits sitting tighter above and below the mean and all above zero. However, it was not until ten years later, in 1998 (when only 3 birds remained), that any intervention strategy was devised, by which time the effort was too late to avoid extinction [23]. Even with patchy data the Systems Behaviour Chart indicates critical changes which can inform decision-making in a new way.

3.5. Detecting the Acceptable Limits of Breeding Processes for a Captive Population of Barbary Lions. The entirely ex situ captive population of lions, thought to be descended from the last wild representatives of the Barbary lion (Panthera leo leo), was founded from individuals in the Moroccan Royal collection. The animals were spread across zoos in North America and Europe until 1979; thereafter, with transfers of animals out of many institutions, all animals (other than those remaining in the Moroccan collection) are found exclusively in Europe [24]. The birth data for the European population shows a perceptible change in the system from 1999 (Figure 5), when efforts were made to rebuild the European zoo population. Although, even in recent years, (with lower birth rates) data still falls within "acceptable" natural limits, from a conservation management viewpoint, the breeding process should be developed such that the lower natural limit rises above zero. Clearly other systemic effects (e.g., gender of cubs, relatedness, genetics, demographics, cub survival rates, and death rates in adults) need to be understood. The System Behaviour Chart identifies that the system is currently improved, but, should a guarantee of continued new births be required, further improvements are needed to ensure that the lower natural limit rises above zero.

\section{Conclusions}

Systems Behaviour Charts and the associated criteria for analysing data are a technique which can support a better

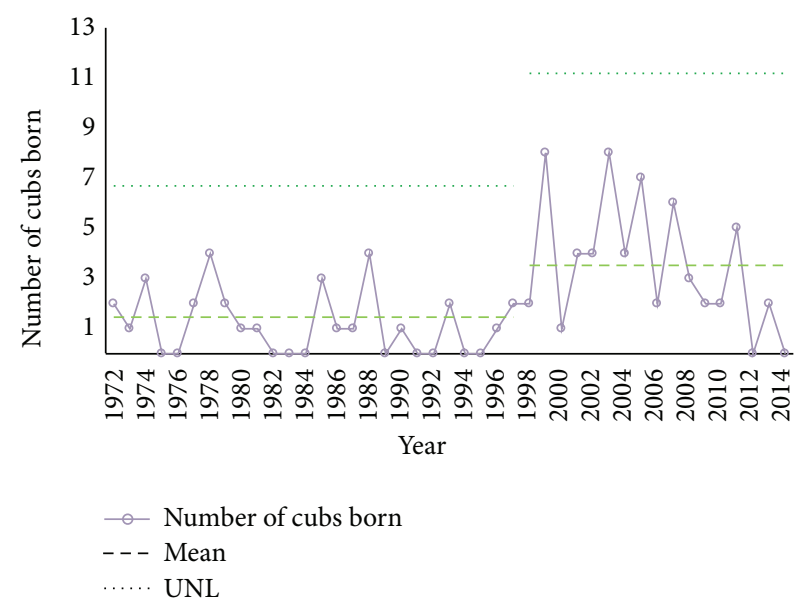

FIGURE 5: Changes in breeding output of the captive zoo population of Moroccan Royal Lions (data from [24]).

operational understanding of effective conservation management in ecosystems. In each of the well-known cases presented, new insights are achieved which offer practical implications for operational management of conservation. The methods for using System Behaviour Charts must sit alongside clear decision-making and an understanding of how to develop short-term conservation goals in line with a clear conservation purpose. The techniques for developing System Behaviour Charts and conducting visual analysis as part of a Systems Thinking approach offer a number of opportunities for conservation leaders: detecting vulnerability in cryptic species, earlier detection of dangerous decline, identifying signals of improvement to encourage effort, identifying stable systems, and detecting important changes in a system. There are many other archetypes of conservation for which System Behaviour Charts could provide useful insight as well as being of practical utility.

Systems Behaviour Charts are a tool which can support practitioners with new, straightforward analytical techniques to make decisions based upon an understanding of the "voice of the ecosystem," namely, what data is telling us is happening, rather than practitioners relying upon more arbitrary dissection of data based upon other priorities, opinions, assumptions, or methodological preferences. In essence the Systems Behaviour Chart enables sequential hypothesis testing which itself is an essential element in improving conservation decision-making. The systems behaviour approach encourages the conservation manager to use empirical data from the target system of interest to inform knowledge and to better understand the impact of operational activity.

\section{Conflict of Interests}

The author declares that there is no conflict of interests regarding the publication of this paper. 


\section{Acknowledgments}

The author thanks Monica Stalio for preparation of Florida manatee data and Adrian Harland and Nobuyuki Yamaguchi for material on Moroccan Royal Lions.

\section{References}

[1] C. N. Cook, M. B. Mascia, M. W. Schwartz, H. P. Possingham, and R. A. Fuller, "Achieving conservation science that bridges the knowledge-action boundary," Conservation Biology, vol. 27, no. 4, pp. 669-678, 2013.

[2] T. G. Martin, S. Nally, A. A. Burbidge et al., "Acting fast helps avoid extinction," Conservation Letters, vol. 5, no. 4, pp. 274280, 2012.

[3] S. A. Black and J. A. Copsey, "Does Deming's 'system of profound knowledge' apply to leaders of biodiversity conservation?" Open Journal of Leadership, vol. 28, no. 5, pp. 1139-1141, 2014.

[4] D. Nutt, “This week's section," Science, vol. 348, no. 6239, pp. 1062-1064, 2015.

[5] W. E. Deming, The New Economics for Industry, Government, Education, MIT Center for Advanced Engineering Study, Cambridge, Mass, USA, 2nd edition, 1994.

[6] P. Scholtes, The Leader's Handbook: A Guide to Inspiring Your People and Managing the Daily Workflow, McGraw-Hill, New York, NY, USA, 1998.

[7] W. A. Shewhart, Economic Control of Quality of Manufactured Product, Van Nostrand Company, New York, NY, USA, 1931.

[8] D. Wheeler, Understanding Variation: The Key to Managing Chaos, SPC Press, Knoxville, Tenn, USA, 2000.

[9] J. Seddon, Freedom from Command and Control, Vanguard Press, Buckingham, UK, 2005.

[10] L. W. Morrison, "The use of control charts to interpret environmental monitoring data," Natural Areas Journal, vol. 28, no. 1, pp. 66-73, 2008.

[11] S. A. Black, J. J. Groombridge, and C. G. Jones, "Leadership and conservation effectiveness: finding a better way to lead," Conservation Letters, vol. 4, no. 5, pp. 329-339, 2011.

[12] E. T. Game, E. Meijaard, D. Sheil, and E. McDonald-Madden, "Conservation in a wicked complex world; challenges and solutions," Conservation Letters, vol. 7, no. 3, pp. 271-277, 2014.

[13] G. Box and T. Kramer, "Statistical process monitoring and feedback adjustment-a discussion," Technometrics, vol. 34, no. 3, pp. 251-267, 1992.

[14] G. Box and S. Narasimhan, "Rethinking statistics for quality control," Quality Engineering, vol. 22, no. 2, pp. 60-72, 2010.

[15] S. A. Black, J. J. Groombridge, and C. G. Jones, "Using better management thinking to improve conservation effectiveness," ISRN Biodiversity, vol. 2013, Article ID 784701, 8 pages, 2013.

[16] R. L. Wallace, “The Florida Manatee recovery program: uncertain information, uncertain policy," in Endangered Species Recovery: Finding the Lessons, Improving the Process, T. W. Clark, P. P. Reading, and A. L. Clarke, Eds., pp. 131-156, Island Press, Washington, DC, USA, 1994.

[17] R. L. Reep and R. K. Bonde, The Florida Manatee: Biology and Conservation, University Press of Florida, Gainseville, Fla, USA, 2006.

[18] K. Tripp, "Record Manatee Mortality in 2010," Manatee News, Save the Manatee Club, May 2015, http://www.savethemanatee .org/news_feature_record_mortality_10.html.
[19] N. F. R. Snyder, J. W. Wiley, and C. B. Kepler, The Parrots of Luquillo: Natural History and Conservation of the Puerto Rican Parrot, Western Foundation of Vertebrate Zoology, Los Angeles, Calif, USA, 1987.

[20] 110 Success Stories for Endangered Species Day 2012: Puerto Rican parrot (Amazona vittata), March 2015, http://www.esasuccess.org/caribbean.shtml.

[21] Endangered Species Act Works: Puerto Rican parrot Amazona vittata, 2015, http://www.biologicaldiversity.org/campaigns/esa _works/caribbean.html.

[22] P. W. Sherman and M. C. Runge, "Demography of a population collapse: the Northern Idaho ground squirrel (Spermophilus brunneus brunneus)," Ecology, vol. 83, no. 10, pp. 2816-2831, 2002.

[23] S. A. Black, H. M. R. Meredith, and J. J. Groombridge, "Biodiversity conservation: applying new criteria to assess excellence," Total Quality Management \& Business Excellence, vol. 22, no. 11, pp. 1165-1178, 2011.

[24] S. Black, N. Yamaguchi, A. Harland, and J. Groombridge, "Maintaining the genetic health of putative Barbary lions in captivity: an analysis of Moroccan Royal Lions," European Journal of Wildlife Research, vol. 56, no. 1, pp. 21-31, 2010.

[25] E. Clarke, R. Davis, S. Davis et al., Creating and Using Control Charts (For Improving Performance), Vanguard Education Limited, Buckingham, UK, 1998.

[26] W. E. Deming, "Foreword," in Statistical Method from the Viewpoint of Quality Control, W. A. Shewhart, Ed., Dover Publications, New York, NY, USA, 1967. 

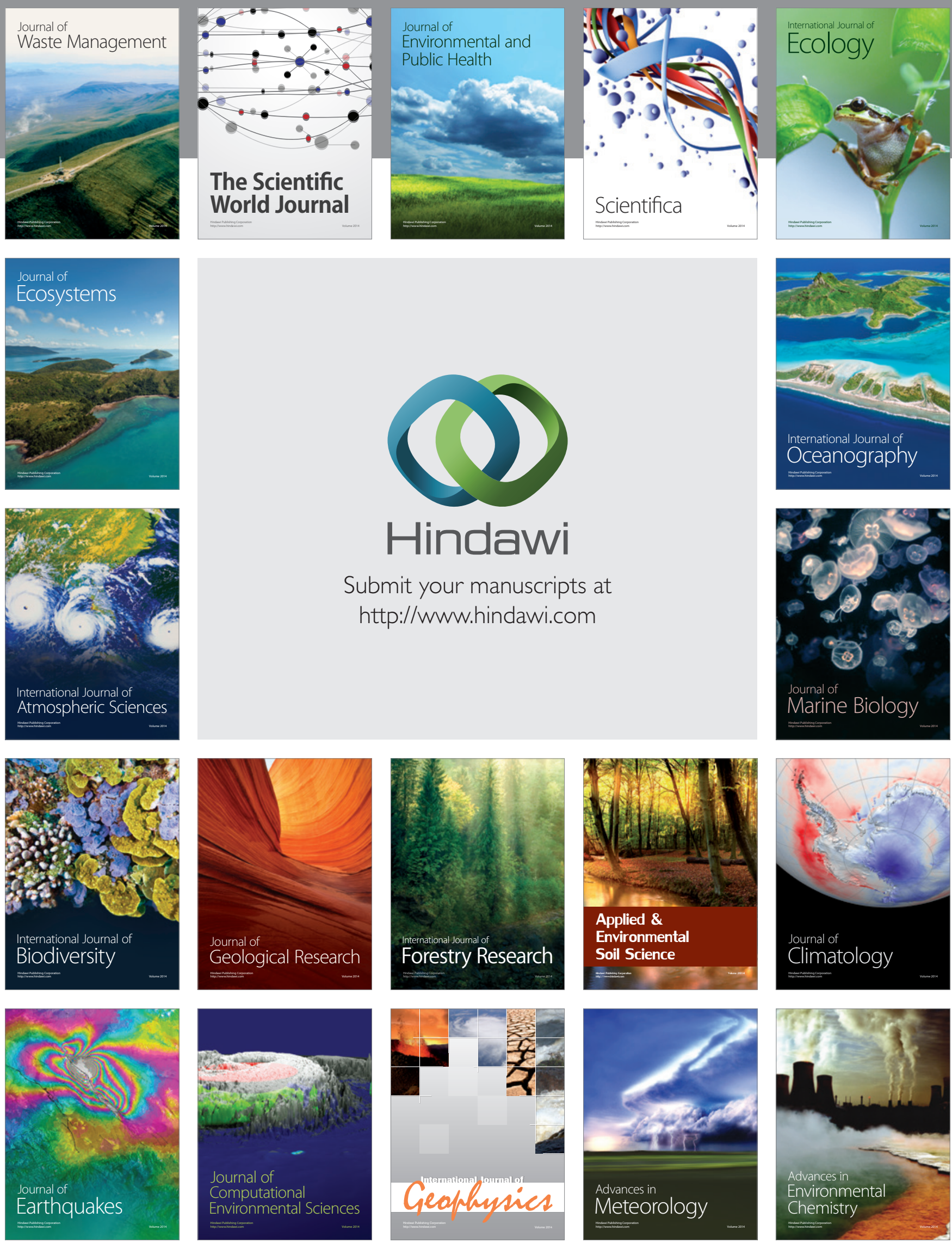